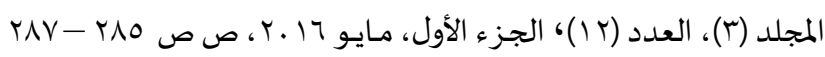
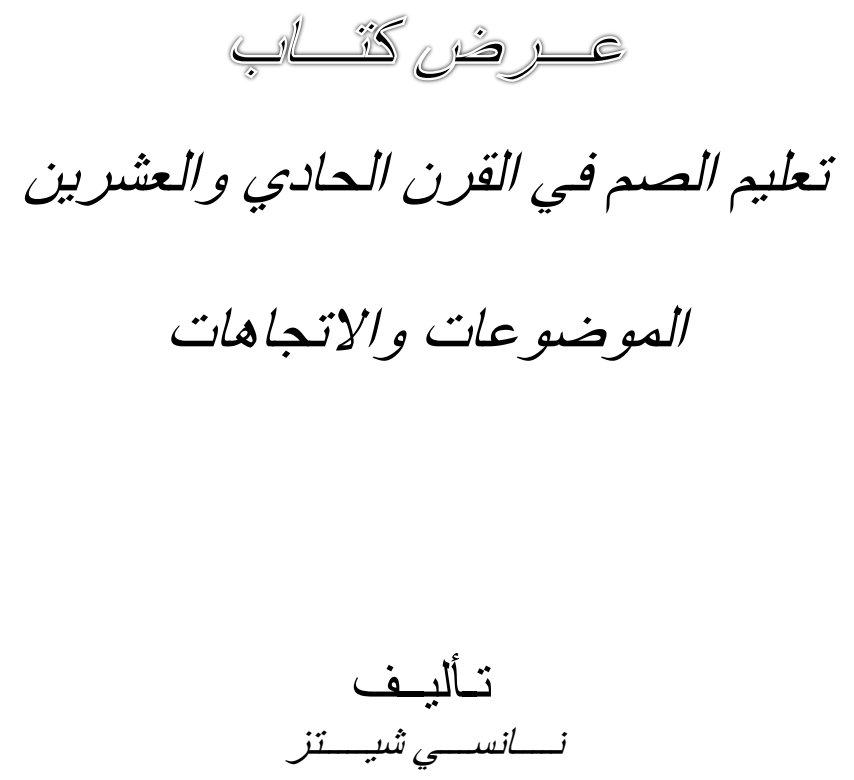

ترجمة

الاستاذ الدكتور / طارق الريس

DOI: 10.12816/0029013 


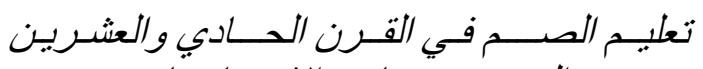

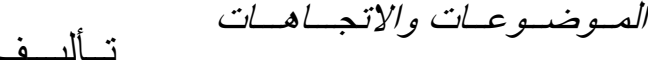

شيـن

\section{DOI: 10.12816/0020695}

$$
\begin{aligned}
& \text { عنـــــــــان الكتــــاب: } \\
& \text { تعليم الصم في القرن الحادي والعشرين " الموضهوعات والاتجاهات" }
\end{aligned}
$$

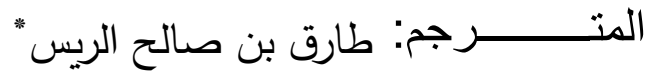

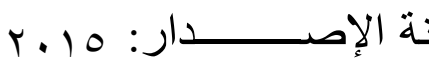

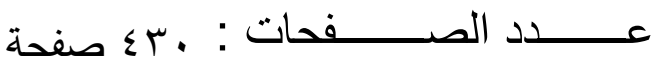

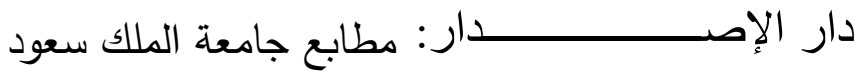

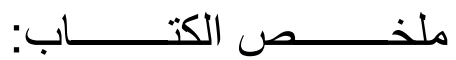

يجتاز تعليم الصـم في القرن الحـادي والعشرين تحولا سـريعا، وذلك في المقام الأول

نتيجة لمـا يشهـده العـالم من تقدم تقني كبير وفرص تربويـة إبداعيـة، فضـلا عن تراجع الحدود الثقافية. ومع تطور مجال تعليم الصم إلى تخصص علمي معقد ومتعدد الأوجه، يتحتم على المهنيين المستقبيين والحاليين أن يتحملوا المسئولية عن تزويد جماعة الطلاب بالأسـاس اللازم لتمكينهم مـن النجـاح أكاديميـا واجتماعيـا ومهنيـا. وفي الوقت نفسـه الذي يقدم فيـه المربـون المؤهلون والمترجمون وموظفو الدعم الآخرون التدريس وخدمات الدعم للطلاب الصم وضعاف السـمع، بـات عليهم أيضـا أن يرفعـوا مستوى التحدي ويقلصـوا فجـوة التحصسيل التي غالبـا مـا تقصل هؤلاء الطلاب عن الطلاب العاديين. وقد كُتبب هذا الكتاب من أجل تلك الأهداف. يعمل المهنيون اليوم مـع الطـلاب في بيئات متعددة، تمتد مـن المدارس الداخليـة إلى فصول الدمج الكلي included classrooms، ويواجهون طلابا لا يقلون تنوعا عن البيئات التي يعملون فيهـا. وهؤلاء المهنيون الذين يمثلون أفرادا مـن خلفيـات عرقيـة وثقافيـة ولغويـة متتوعة، يدخلون البيئة التربوية مزودين بمجموعات من المهارات الشخصية.

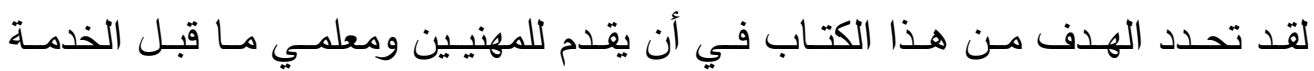
والمترجمين والمستشارين والموظفين الآخرين في مجال تعليم الصم منظورا واسعا ومتوازنا حول 
الموضوعات والاتجاهات الحالية التي تسبح اليوم في فضاء المجال. ونظرا لأن الكتاب يغطي مجموعة واسعة من الموضوعات، منها المنظورات التربوية والمبادئ النفسية-الاجتماعية وأنماط التواصـل وأدوات الســع المزروعـة cochlear implants والتقدم في تقنيـة سـماعات الأذن hearing-aid وغيرهـا مـن الموضـوعات الحاليـة ذات الصـلة، سـيجد القـارئ نفسـهـ أمـام مشـهـ بانورامي لمجال معقد، وليس مجرد تحليل معمق للأبعاد الرئيسية. لكل ذلك يعد هذا الكتاب مرجعا حول كثير من الأبعاد التي يتضمنها مجال تعليم الصم. ونظرا لأن الكتاب كُتب لكي يكون عونا للتدريس والتعلم، سيجد القارئ أن المفاهيم الأساسية تتواتر في مواقف مختلفة، وأن الرسوم الإيضاحية وبعض المفاهيم تتكرر في سياقات متباعدة بهدف تعزيز الفهم وتحسين القدرة على الاحتفاظ بالمعلومات. إن المهنيين في مجال تعليم الصم عندما يجتمعون ويتبادلون همومهم ورؤاهم للمستقبل، تكثف القصص التي يقصونها والخلفيات التي يأتون منها عن فسيفساء كثيرة الألوان. فتجد بين المشـاركين أفرادا صـما يمثلون تراث ثقافي ولغوي ثري، وتجد أيضـا مهنيـين صـم وسـامعين hearing حريصين على معرفة أفضل الطرق لخدمة طلابهم. فخلفيات هؤلاء المهنيين لا تقل تتوعا عن خلفيات الأفراد الذين يخدمونهم. ولا يخفى عن القارئ التحدي الذي يفرضـه على أي مؤلف تأليف كتاب تأسيسي يخاطب احتياجات تلك الجماعة المتتوعة من المهنيين. وكل مـا آمله هو أن يثير المحتوى الوارد في الصفحات التالية اهتمام القارئ لكي يستكشف المزيد حول الموضوعات المتضمنة.

وتضمن الكتاب خمس عشرة فصلاً، حيث تتاول الفصل الأول تعليم الصم في القرن الحـادي والعشـرين الموضـوعات والاتجاهـات والتقنيـة مراجعـة مـوجزة، و نـاقش الفصـل الثاني الأسـاطير والتصورات الخاطئة حول الأشخاص الصـ، والفصل الثالث نظرة على مجال تعليم الصم أين كنا وأين أصبحنا، والفصل الرابع علم السمع وفقد السمع الخصائص الصوتية للكلام وانتقال الصوت، الفصل الخامس الدينامية الأسرية : الاستجابة للتشخيص والعلاقات الثخصية وتأثيرها على الوحدة الأسرية، والفصل السـادس اكتساب اللغة، والفصل السـابع التقييم السمعي 
وسماعات الأذن وأدوات السمع المزروعة والتقنية الحديثة، والفصل الثامن البيئات التربوية من الماضـي إلـى الممارسـات الحاليـة، والفصـل التاسـع معرفـة القـراءة والكتابـة، والفصـل العاشـر المعرفة، العمليات الفكرية والنمو العقلي، و الفصل الحادي عشر النمو الثخصي والاجتماعي والثقافي، والفصل الثاني عشر الاقتصاد وفرص ما بعد الددرسة الثانوية واتجاهات التوظيف، و الفصل الثالث عشر الأشخاص الصم ذوي الإعاقات الإضافية الانتشار والخصائص، والفصل

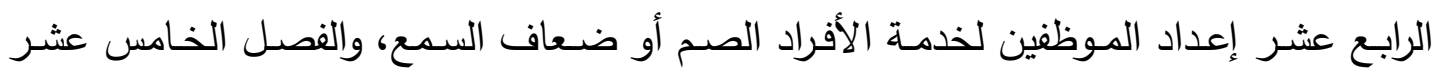

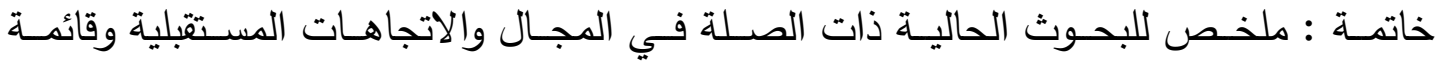

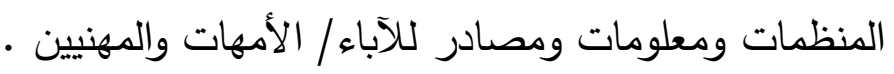
وأخيراً، يعد هذا الكتاب من أحدث الكتب في مجال تربية وتعليم الصم وضعاف ولتهاء السمع، ويتتاول احسث التوجهـات الحديثـة في المجـال، ويلبـي اهتمامـات اعضــاء هيئـة التـدريس والبـاحثين والمعلمين في مجال العوق السمعي. و الله من ور اء القصد, وهو الهادي إلي سواء السبيل

$$
\text { طارق بن صالح الريس المـترج }
$$

